\title{
Camino a la paz: repertorios simbólicos testimoniales de una nación en transición
}

Path to peace: testimonial symbolic repertoires of a nation in transition ${ }^{1}$

\section{ELVIRA SÁNCHEZ-BLAKE}

MiCHIGAN STATE UNIVERSITY · sblake@msu.edu

Doctora y profesora asociada del Department of Romance and Classical Studies de la Michigan State University, EE.UU.

\section{YENIFER LUNA GÓMEZ}

UNIVERSIDAD DEL VALLE·yenifer.luna@correounivalle.edu.co

Investigadora social en el grupo de Acción Colectiva y Cambio Social, ACASO, en la

Universidad de Valle, Colombia.

RECIBIDO: 16 DE NOVIEMBRE DE 2015

DOI: 10.7203/KAM.6.7279

ACEPTADO: 1 DE DICIEMBRE DE 2015

ISSN: 2340-1869

Resumen: En Colombia se han dado en los últimos años una variedad de repertorios simbólicos de memorias del trauma que ha vivido el país como resultado del conflicto armado. Estos repertorios se manifiestan en diversas expresiones culturales y estéticas con el fin de interpelar y transformar las experiencias sufridas por las víctimas de la violencia. Son prácticas de reparación y resistencia como antídoto contra la impunidad y el olvido. En este ensayo se propone que los repertorios simbólicos son las nuevas formas del testimonio del siglo veintiuno. Dichos repertorios se apropian de los métodos y estrategias del testimonio para expresar una urgencia y una solidaridad hacia un objetivo común, la del clamor por la paz y la reconciliación con la justicia social.

Palabras claves: Colombia, repertorios simbólicos, performance, testimonio.
Resumen: Colombia has seen in recent years the surge of a variety of symbolic repertoires from traumatic memory experienced by the country as a result of the armed conflict. These repertoires compose diverse aesthetic and cultural expressions that challenge and transform the experiences suffered by the victims of violence. These are practices of reparation and resistance as an antidote against impunity and oblivion. This essay proposes that the symbolic repertories are the new forms of testimony of the twenty-first century. The symbolic repertoires appropriate the methods and strategies of the testimony genre to express an urgent need and solidarity toward a common goal, the clamor for peace and reconciliation with social justice.

Palabras claves: Colombia, Symbolic Repertoires, Performance, Testimony.

${ }^{1}$ Este artículo fue posible gracias a una beca de investigación de la Comisión Fulbright y del auspicio de la Universidad del Valle (Cali, Colombia) durante el primer semestre del 2015. 


\section{Introducción}

Colombia ha vivido uno de los conflictos sociales y políticos de más larga duración en el continente americano, con una confrontación de múltiples actores armados: guerrilla, narcotráfico, paramilitarismo, intervención extranjera y violencia de estado. Esta complejidad del conflicto ha generado miles de víctimas en todos los niveles y estratos del país: víctimas de la violencia armada, de desapariciones, desplazamientos, violaciones y abusos de poder. Actualmente se avanza en la negociación de uno de los acuerdos de paz más esperados, el del cese a las acciones armadas entre el gobierno y las Fuerzas Armadas Revolucionarias de Colombia-FARC- uno de los movimientos revolucionarios más antiguos de la región².

En la última década, Colombia ha visto el surgimiento de numerosas organizaciones de víctimas trabajando por la paz. Estas organizaciones han desarrollado un amplio espectro de iniciativas de memoria que se representan en repertorios diversos a través del arte, la narración oral, el teatro, la pintura, la danza, y rituales de diferente naturaleza. En la gran mayoría, estos colectivos están compuestos por mujeres, por ser ellas las víctimas y a la vez, las supervivientes, las que han experimentado las pérdidas y el dolor. Al unirse en forma colectiva en iniciativas de resistencia han adquirido poder y liderazgo en sus comunidades, lo que les ha permitido surgir y convertirse en agentes culturales de cambio, y en algunos casos en las representantes de sus regiones ante foros políticos.

Este ensayo indaga específicamente en la forma de cómo los repertorios simbólicos que llevan a cabo diversas organizaciones de mujeres están generando una transformación a nivel de sociedad y cómo esta transformación se refleja en un empoderamiento. Es decir, que las mujeres experimentan una evolución de víctimas a agentes culturales de cambio a través de la acción colectiva.

\section{Testimonios del siglo XXI}

Cuando John Beverly declaró el fin del género del testimonio en Latinoamérica porque según él, el carácter de urgencia del género había concluido para la región (Beverly, 1996: 281), no se imaginó que el testimonio apenas hacía su entrada en otras regiones, donde las características del mismo abrían una ventana hacia los sujetos en situaciones de conflicto. Tal fue el caso de Colombia, en donde a partir del año 2000 surge una proliferación de testimonios, especialmente de mujeres, que escogen esta forma de expresión para dar a conocer sus experiencias de dolor y resistencia. En estos casos, el testimonio femenino se aproxima más a la definición dada por George Yúdice cuando señala que la función más

\footnotetext{
${ }^{2}$ En el momento de escritura de este artículo (noviembre del 2015), se espera la firma de un acuerdo bilateral del cese al fuego para marzo del 2016, con la esperanza de una paz duradera y definitiva. Las negociaciones entre gobierno y las FARC se iniciaron en el 2012 y actualmente se adelantan en La Habana, Cuba.
} 
importante del testimonio es la de servir de vínculo solidario entre diversas comunidades, atravesando fronteras e identidades en pro de una transformación democratizadora (Yúdice, 1992: 232).

Esta definición amplia e incluyente se ajusta a las transformaciones de tecnología y de representación que demanda el nuevo milenio. En una era donde los medios sociales irrumpen en escena con nuevas formas de comunicación, el testimonio ya no es simplemente documental, ni se limita al narrador que habla en función de un sujeto en condición de subalternidad. Por el contrario, como demuestran los nuevos estudios del género, muchas de estas narrativas, sobre todo las escritas por mujeres, son fronterizas, presentan una multiplicidad de estilos, discursos y géneros que las hacen anómalas (Kaminski, 1993: 61). Al mismo tiempo, como señala Constanza López Baquero, "el hecho de que el testimonio se debata entre lo ficticio y lo fáctico, lo literario y lo no-literario, lo fabulado y lo relatado, lo oral y escrito, hace posible precisamente su carácter descentrado y disperso" (López Baquero, 2012: 30).

López Baquero, una de las estudiosas en abordar el testimonio femenino colombiano, amplía la categorización del mismo hacia la memoria y el trauma que implica el hecho de narrar experiencias dolorosas desde la subjetividad femenina:

Los testimonios femeninos se enfrentan a una historia oficial que niega y oculta. Las autoras, tanto como sus historias, han corrido el riesgo de que se les acuse de mentirosas y sobrevivido el silenciamiento de diversas formas... Además, han dado la cara a una sociedad que no acepta que esos horrores puedan ocurrir en el país (López Baquero, 2012: 36).

El testimonio femenino debe incluir la memoria, el cuerpo y la sanación de los traumas causados por la violencia política. López Baquero concluye que "los testimonios no son relatos totalizadores, pero en conjunto tienen la capacidad de hacer visibles los traumas de una nación” (López Baquero, 2012: 39). En la misma línea, Veena Das, señala que los testimonios deben entenderse desde la cotidianidad de los hablantes estructurados por tradiciones simbólicas. Es por eso que las formas testimoniales no se pueden entender desde el análisis textual, sino que hay que comprenderlos en su sociabilidad. Para Das, las expresiones testimoniales producto de memorias reprimidas propician zonas de silencio que se deben encauzar en otras manifestaciones. Muchas veces, esas zonas solo pueden aflorar dentro de experiencias sociales que privilegian la solidaridad. Por eso, el testimonio se debe abordar a través de complejas relaciones entre el cuerpo y el lenguaje porque en esa intersección se encuentran los recursos "para decir y mostrar el dolor y ofrecer testimonio al daño infligido en el tejido social” (Das, 2008: 47).

En este sentido, las nuevas formas testimoniales plantean una relación cuerpo-memoriaperformance. La agencia que se construye por medio de la experiencia colectiva para rescatar la memoria desde el cuerpo con el fin de convertir los traumas en repertorios simbólicos de empoderamiento y de transformación a nivel de nación. 
Pero, ¿cómo se construye esa memoria desde el cuerpo? La definición de repertorios y performances que designa Diana Taylor, son la que en nuestra opinión acoge las prácticas que surgen desde el cuerpo para resignificar experiencias traumáticas en forma de expresión artística que transforman el dolor en agencia y solidaridad a nivel colectivo.

\section{Repertorios simbólicos del testimonio}

Diana Taylor distingue entre repertorios y archivos como fuentes de conocimiento. Los repertorios son las prácticas y experiencias que parten del cuerpo y la cotidianidad (la praxis) y los archivos son las fuentes documentales tales como libros, fotografías y formas perdurables del saber (episteme) (Taylor, 2003: 16-17). Los repertorios se definen como las expresiones creativas que incluyen la oralidad, el movimiento, la danza, y el canto, el teatro, la puesta en escena, actos usualmente considerados efímeros.

Etimológicamente, repertorio significa "tesoro o inventario", lo cual permite agenciar por parte del individuo en los actos de descubrir y producir significados. El repertorio requiere presencia, es decir, la participación activa de los sujetos en la producción y reproducción de conocimiento, estar allí, ser parte activa del mismo. El repertorio transmite y mantiene coreografías de significado, los cuales mantienen el sentido aun a través de los cambios que suceden en el tiempo (Taylor, 2003: 20). Estos repertorios se manifiestan por medio de lo que Taylor llama "performances", lo que permite a la gente participar en la producción y reproducción de conocimiento y hacer parte de su transmisión.

Si consideramos que estas formas expresivas y performativas transmiten la memoria por medio de una producción de significados que se originan en el cuerpo y los sentidos, y que contienen elementos argumentales y narrativas no reducibles al lenguaje, podríamos proponer un nuevo tipo de discurso denominado "repertorios simbólicos del testimonio". Esta categoría sería una forma de canalizar las estrategias usadas por las organizaciones de víctimas en su necesidad de visibilizar el clamor colectivo en busca de conciliación. Dado el momento histórico que vive Colombia de urgencia y de clamor colectivo dos condiciones clásicas del testimonio- los repertorios simbólicos testimoniales se constituyen en una nueva definición que responde a los desafíos del siglo veintiuno.

Esta idea surge como una respuesta a la necesidad de nombrar las iniciativas de memoria surgidas en los últimos años en Colombia que no se acogen a prácticas narrativas estructuradas ni se ubican claramente dentro de un lenguaje que las designe uniformemente. Varios estudios propiciados por el Grupo de Memoria Histórica de la Comisión Nacional de Reparación y Reconciliación (CNRR), y por instituciones como el Centro Internacional para la Justicia Transicional (ICJT), utilizan lenguajes diversos para seleccionar y catalogar las formas expresivas de memoria. Si el informe del ICJT se refiere a 
"iniciativas no oficiales de memoria" y a "repertorios vivos", el Grupo de Memoria Histórica habla de "iniciativas de memoria". Otro informe del PNUD ha denominado como "Banco de buenas prácticas" a las acciones impulsadas por comunidades, organizaciones sociales, iglesias, entidades estatales y la comunidad internacional, encaminadas a acompañar a las víctimas, desincentivar a los jóvenes de vincularse a la guerra, facilitar la reinserción de los combatientes desmovilizados e instaurar prácticas y lenguajes de paz, entre otras cosas. ${ }^{3}$

Los autores del informe del Grupo de Memoria Histórica definen estas iniciativas como “procesos permanentes, impulsados por movimientos de víctimas como prácticas puntuales de resistencia que implican formas de subjetividad colectiva y que buscan restaurar la dignidad y la cotidianidad laceradas por la violencia" (CNRR: 2009,18). Las iniciativas reseñadas siguen la definición de Elizabeth Jelin (2000), quien habla sobre "vehículos de la memoria", refiriéndose tanto a libros y archivos como a expresiones y actuaciones "que antes de representar el pasado, lo incorporan performativamente" (Jelin, 2000: 37). Al hacerlo, se movilizan sentidos, se ubican hitos espaciales y temporales y se le da un significado, un propósito y un futuro al acto y al trabajo de la memoria. Son esfuerzos colectivos que establecen relaciones entre el pasado, el presente y el futuro, y entre los dolores de las víctimas, los hechos y sus responsables. Los autores hacen énfasis en el carácter "fundacional” de la memoria refiriéndose a "iniciativas" antes que a "trabajos". Estas iniciativas tienen en común que miran hacia adelante sin ignorar el pasado, afirman en el presente un futuro abierto que al mismo tiempo restauran y renuevan las formas de vida comunitaria (CNRR: 2009,18).

En un informe del ICJT titulado "Recordar el conflicto: iniciativas no oficiales de la memoria", Felix Reátegui afirma que la memoria es un factor constituyente del espacio público que comunica lo social con lo político. Para este autor, la memoria es una sustancia social que puede ser eficaz tanto para la consolidación de un poder como para desafiarlo, transformarlo o desestabilizarlo. Por lo tanto, "se convierte en un ingrediente importante de la malla simbólica en la que se sostienen nuestros ordenamientos sociales, ya sean oficiales o de individuos y colectividades" (Reátegui, 2009: 24-25). Un elemento fundamental que Reátegui considera paradójico es comprender cómo a partir de la violencia, la producción de la memoria nacional tradicionalmente generada por las élites ilustradas e intelectuales, se ha transformado a "una irrupción reciente de la memoria de las víctimas: de sus testimonios y de las formas propias, no académicas, no letradas, de rendir versiones del pasado en la esfera pública” (Reátegui: 2009: 27).

${ }^{3}$ Ver www.saliendodelcallejon@pnud.org.co 
Reáteguí señala que el proceso que se está dando en Colombia responde a los procesos de violencia que ha vivido no solo Colombia, sino el continente. Se trata de memorias heterogéneas y diversas: "memorias que no necesariamente privilegian la expresión verbal, sino que se sienten mejor expresadas en la acción y en el performance, memorias que reposan sobre supuestos diversos acerca de la relación con el poder y el estado” (Reáteguí: 2009: 27).

Por su parte, María Victoria Uribe en su ensayo, "Iniciativas no oficiales: un repertorio de memorias vivas", hace una recopilación de los repertorios vivos que se han dado en Colombia a lo largo del territorio y que intentan preservar o transformar experiencias traumáticas relacionadas con el conflicto armado. Según Uribe, se trata de prácticas, representaciones y significados que construyen las comunidades y organizaciones afectadas por la violencia con el fin de hacer público su dolor y denunciar las injusticias de las que han sido objetos. Son prácticas de resistencia contra la impunidad y el olvido e inciden en la recuperación de la autoestima y la confianza (Uribe, 2009: 44). Uribe hace una categorización de lo que ella denomina "repertorios de memorias vivas". Algunas son prácticas que utilizan el cuerpo y los sentidos; bailes y danzas. Tal es el caso de los indígenas Kankuamos del Caribe colombiano, que bailan para no olvidar. Las marchas, plantones, peregrinaciones y las llamadas "trochas por la vida”. Estas últimas son caminatas abriendo trochas o senderos convocadas por las asociaciones de víctimas de los municipios más afectados por la violencia.

Dentro de la categoría de los performances, Uribe sigue a Taylor en cuanto a la definición de la misma como "un tesoro de inventiva que permite la agencia individual" (Uribe, 2009: 58). Esta categoría incluye tejidos, pinturas y dibujo, fotografías, cartografías, mapas mentales, álbumes de memoria, iniciativas sonoras y canciones y programas radiales. También se refiere a las iniciativas textuales que incluyen los libros de memoria y archivos documentales. En la categoría de monumentos se cuentan los museos de la memoria que se han creado en el territorio: el salón Nunca más de Granada, Antioquia, el museo de la memoria en Medellín y el Centro de memoria histórica de Bogotá.

En este ensayo se analizan varios tipos de repertorios simbólicos testimoniales en cuatro manifestaciones: teatro, arte, tejidos y rituales. Se parte del presupuesto expresado por Taylor, en el sentido de que "el repertorio constituye un conocimiento incorporado, un aprendizaje desde el cuerpo y a través de él, así como un medio de crear, preservar y transmitir conocimiento” (Taylor, 2003: 16).

\section{Antígona, Tribunal de Mujeres}

El teatro se ha convertido en años recientes en uno de los repertorios culturales con mayor incidencia en la forma de testimoniar el conflicto armado y de concienciar al público sobre las maniobras del poder oficial. Uno de los casos más emblemáticos es el la producción de la obra de creación colectiva, 
Antígona Tribunal de Mujeres, bajo la dirección de Carlos Satizábal, producida por el grupo Tramaluna, asociado a la Corporación Colombiana de Teatro ${ }^{4}$.

La obra Antígonas tribunal de mujeres, estrenada en Bogotá en marzo del 2014 retoma el mito clásico de Antígona de Sófocles para denunciar cuatro crímenes de estado en Colombia. El primero es el caso de los llamados "falsos positivos" ${ }^{5} \mathrm{El}$ segundo caso es el genocidio de los integrantes del Partido Unión Patriótica; el tercero, es la persecución a abogadas defensoras de derechos humanos, y el cuarto se refiere a los montajes judiciales a líderes estudiantiles universitarios.

En la obra el mito milenario de Antígona ${ }^{6}$ se reproduce acogiendo los relatos de las madres y familiares de estas víctimas para transmitir un mensaje con una dimensión mítica y poética. Para el caso de esta obra se escogieron colectivos de mujeres que denunciaban la desaparición de sus hijos o familiares. El equipo creativo estuvo integrado por mujeres sobrevivientes del genocidio de la Unión Patriótica ${ }^{7}$, las Madres de Soacha ${ }^{8}$, abogadas defensoras de los derechos humanos y por algunos artistas de la Corporación Colombiana de Teatro.

La obra presenta a cada mujer relatando su testimonio real al público y portando algún objeto que perteneció a su ser querido, sea este, hijo, marido o hermano. El testimonio viviente se inicia presentándose y a continuación relata cómo y quién fue el ser querido desaparecido o asesinado. Uno de los testimonios más llamativos es el de María Sanabria, una de las Madres de Soacha, cuyo hijo de dieciséis años fue secuestrado de un parque cercano a su casa junto con otros muchachos del barrio. Estos jóvenes fueron transportados a Ocaña, en el Norte de Santander, zona fronteriza con Venezuela. Allí fueron torturados y asesinados por las fuerzas militares. El hijo de María Sanabria en cuestión, era un joven con una discapacidad física y cognitiva. El lado derecho de su cuerpo estaba totalmente

\footnotetext{
4 Durante varios años los artistas de la Corporación Colombiana de Teatro que dirige Patricia Ariza, ha trabajado en la construcción de relatos poéticos y políticos de las experiencias traumáticas por la población civil en medio del conflicto colombiano. Véase, http://www.corporacioncolombianadeteatro.com.

5 Como "falsos positivos" se denominó al asesinato de jóvenes de barrios marginales por parte de militares que los hacían pasar por guerrilleros para ganar prebendas del estado durante los mandatos sucesivos de Álvaro Uribe Vélez (2002-2010).

${ }^{6}$ En la tragedia de Sófocles, Antígona, hija de Edipo y Yocasta, desafía a Creonte, Rey de Tebas, quien había prohibido bajo pena de muerte enterrar a Polinices, hermano de Antígona, por haber traicionado su patria. La decisión de Antígona de darle sepultura a su hermano, para que su espíritu no vagara por la tierra eternamente, le acarrea el suplicio de ser enterrada viva y resulta en su muerte por suicidio. La trama de la tragedia se ha convertido en un mito que se recrea sucesivamente en zonas afectadas por violencia, tiranías y abusos de poder.

7 Partido político creado cuando se firmó la paz en 1986 entre el gobierno y las FARC, cuyos líderes e integrantes fueron masacrados casi en su totalidad por fuerzas militares y del estado.

8 Las Madres de Soacha es un colectivo integrado por madres de los "falsos positivos", jóvenes que fueron asesinados impunemente haciéndolos pasar por guerrilleros dados de baja en combate. Las Madres de Soacha se constituyó como grupo en el 2010 para denunciar estos hechos por medio de marchas y manifestaciones.
} 
inmovilizado. El muchacho fue señalado por las autoridades de ser uno de los líderes de un batallón guerrillero de las Farc y su muerte aparece como "dado de baja en combate". El hecho de escuchar de viva voz a la madre relatando el caso de su hijo, portando la foto de él es un acto emotivo de denuncia. Además, esta mujer en su testimonio hace contundentes denuncias con nombres y apellidos de los oficiales de alto rango que presuntamente asesinaron a su hijo y pide que se haga justicia. María Sanabria se convierte así en una Antígona en el acto simbólico de desafiar al poder político y de denunciar la injusticia cometida. Al mismo tiempo, su testimonio la señala y la pone en evidencia porque ella, al igual que Antígona, sabe que se somete al juicio de las autoridades por el hecho de retar a los militares que representan el poder y la autoridad. La acción poética teatral performativa se convierte así en un primer gesto de restitución. El hecho de nombrar es restituir el lenguaje y de hacer presente al ausente, restituyendo su memoria, su dignidad y aseverando su condición de víctima de un sistema opresor.

El director de la obra, Carlos Satizábal, describe el mensaje de la obra en estos términos:

El mito de Antígona sirve así de inspiración para poetizar la búsqueda tenaz de los colectivos de madres, mujeres y defensoras de los derechos. Una lucha amorosa en la que las mujeres van transformando el dolor en rebeldía y en acciones poéticas civilizatorias. Es esta transformación son esenciales el relato, la canción, el teatro, la danza, la fuerza misteriosa de la poesía que habla a las fibras más hondas de la vida, del alma, de la memoria personal y colectiva” (Satizábal: 2015: $4)$.

La obra en su totalidad armoniza el acto del performance como repertorio que surge desde el cuerpo: "el cuerpo que canta, que actúa, que habla, que enmudece, y que está presente" (Satizábal, 2015: 4). Esta es una obra que cumple con el postulado de "estar alli" y que no se puede reproducir en un archivo porque no se basa simplemente en un enunciado, sino en la polifonía de múltiples discursos que interrogan al público: "si hay o no en los crímenes de estado un hilo común, si el país, la sociedad es víctima de un proyecto sistemático: del horror como dominación” (Satizábal, 2015: 4).

Esta interrogación viva es mucho más profunda si se tiene en cuenta que los actores son las víctimas reales del conflicto, las que testimonian los dolores desde su cuerpo y desde sus entrañas: dolores y traumas que no surgen de la acción escénica, sino desde la realidad misma. De esta forma, la obra convierte al público en un tribunal, que debe responder ante la tragedia, no a la escénica, sino a la real que vive el país en todas sus dimensiones políticas y sociales. En el cuadro final, Antígona, enterrada viva, afirma ver los hilos, que une cada uno de los casos presentados en un mismo delirio de oro y de sangre (Satizábal, 2015: 4).

Uno de los elementos que ha sido puesto en juicio y cuestionado es la auto-referencialidad de la obra: el hecho de que los personajes víctimas de la violencia hablen por sí mismas desde su experiencia personal. Esto supone un gran trabajo de producción, ya que en el escenario deben comportarse como 
actrices profesionales al lado de otros artistas y deben cumplir con el compromiso escénico. Lo interesante, según Satizábal, es que esto no constituyó un problema para la producción. Las actrices lograron darle la teatralidad necesaria a sus personajes gracias a la solidaridad de grupo y en el proceso se hicieron conscientes de sus propios talentos. Algunas de ellas compusieron las canciones que entonan en el escenario. Así, se revelaron poetas, dramaturgas, creadoras, agentes de su propia historia. Descubrieron su potencial de ser y estar en el mundo. En el escenario la polifonía de voces conforman una sola mujer: "la Antígona contemporánea que condensa en el aquí y el ahora de la acción viva el mito y el canto poética de nuestra propia tragedia colombiana” (Satizábal, 2015: 13).

Como corolario, algunas de estas mujeres, entre ellas María Sanabria, se ha convertido en líder y vocera de su colectivo en la búsqueda de la verdad y justicia. Tuvimos la oportunidad de verla hablando ante grandes audiencias en la Cumbre de Arte y Cultura para la Paz (Bogotá, 6-12 de abril, 2015) y en varios medios de comunicación. El hecho de que las noticias recientes señale a los oficiales que participaron en el asesinato de los jóvenes de Soacha, es un avance en esta búsqueda y una forma de constatar que el repertorio simbólico testimonial se convierte en acción y transformación a nivel individual y colectivo. De este modo, el caso de María Sanabria logra lo que en su más profundo sentido representa el grito de Antígona. En palabras de Judith Butler, "el grito de Antígona es el acto verbal con el que transgrede el orden a través de la apropiación de las mismas normas de poder a las que se opone" (Butler, 2001: 26).

\section{El mural de la Ruta Pacífica}

Uno de los repertorios testimoniales que han encontrado una gran acogida en el medio de las colectividades de mujeres es el de las artes plásticas. El acto de plasmar en un cuadro, pintura o mural las experiencias de trauma y de dolor rescatan la memoria y convierten el recuerdo en esa representación tangible que revive y restituye el trauma que se quiere superar. Este tipo de repertorio en palabras de Taylor, funcionan como actos vitales de transferencia que transmiten un saber social, de memoria y sentido de identidad a través de prácticas culturales y estéticas (Taylor, 2003: 22). Este es el caso del Mural de la Ruta Pacífica, Valle del Cauca ${ }^{9}$, en el cual tuvimos la oportunidad de participar como observadoras. Este mural se creó con el propósito de rescatar la memoria colectiva de las mujeres víctimas del desplazamiento de la zona suroccidente del país. La producción del mural en una zona

\footnotetext{
9 La Ruta Pacífica de las mujeres es una organización de mujeres que se define como "un movimiento pacifista, no armamentista, constructor de una ética de la No violencia, y del reconocimiento de los derechos fundamentales de las mujeres." Sus principios fundamentales son la justicia, la paz, la equidad, la autonomía y el reconocimiento de la otredad. A partir del año 2000 su accionar se extiende a más de 300 organizaciones regionales y locales en todo el país. http:// www.rutapacifica.org.co/
} 
céntrica de la ciudad de Cali pasó por un proceso que incluyó un taller de aprendizaje de técnicas artísticas, selección de imágenes, diseño de las participantes, actividades comunales, limpieza y adecuación de la zona donde se pintó el mural, pintura y celebración del mural concluido. Cabe resaltar que en este caso el proceso fue más significativo que el resultado mismo. Todas las actividades que precedieron la pintura del mural fueron realizadas en forma colectiva. En los talleres, el artista, Eric Ortega y la socióloga, Tatiana Osorio, les enseñaron a las participantes a dibujar desde su propia experiencias. Las mujeres, un poco temerosas al principio, luego con más confianza, plasmaron en dibujos sencillos lo que representó para ellas la salida de sus lugares de origen como víctimas de desplazamiento. Algunas diseñaban una imagen, otras, una serie de cuadros sucesivos, otras representaban los objetos que dejaron atrás, o su casa con sus animales y naturaleza contiguo. La mayoría dibujaba cuerpos o rostros con huellas de dolor. En palabras de Tatiana Osorio, "lo que significa que el conflicto pasa a través del cuerpo de las mujeres: es una experiencia corporal”" ${ }^{\prime 10}$ En medio de estos talleres se generaban lazos de solidaridad y de reflexión sobre las experiencias compartidas. La memoria positiva o ejemplar de la que habla Todorov, se hacía evidente cuando algunas de las participantes comentaban, "ahora puedo contar mi experiencia porque no soy la única". Efectivamente, el estigma de ser desplazadas deja de serlo cuando son varias las que comparten la misma circunstancia y pueden transmitirlo sin recabar en la victimización, sino en el empoderamiento que produce exteriorizar una experiencia colectiva.

La pintura seleccionada para ser el centro del mural fue el de una figura de mujer que sale de su pueblo cargando un bebé en su espalda. La figura frontal se destaca en la pintura por la fuerza de su rostro y la determinación de su mirada. En el centro del pecho se aprecia una casa, significando que lleva su casa en el corazón. El día de la pintura del mural las participantes plasmaron sus diseños alrededor de la figura central. Durante los días previos a la ejecución del mural, se celebraron mingas, que consiste en una olla comunal donde todas participan en la cocción y comparten la comida; exposición artesanal de los productos que tejen y laboran las integrantes del colectivo; cantos y representaciones de artistas invitados. Alrededor de estas actividades sobresalía la energía que produce la solidaridad: la resignificación de saberes y poderes, el crecimiento como individuos y la fuerza de colectividad. Al entrevistar a Ignacia, la mujer cuya pintura fue seleccionada como centro del mural, ella reconoció lo que ha representado para ella pertenecer a una agrupación donde aprende a reconocerse en su identidad de mujer y en sus derechos como persona ${ }^{11}$. Asimismo, destacó el apoyo que ha recibido para superar su dolor y las herramientas que ha encontrado para convertirse en líder de su propia familia y comunidad.

\footnotetext{
${ }^{10}$ Entrevista con Tatiana Osorio. (Abril 15, 2015, Cali, Colombia).

11 La entrevista con Ignacia M. Roca Ariza (15 de abril del 2015, Cali, Colombia).
} 
Para Ignacia, el hecho de plasmar su propia experiencia en una pintura significa exteriorizar su dolor en forma simbólica al tiempo que su condición de desplazada deja de ser un estigma para convertirse en un instrumento de restitución. En esta forma, el repertorio artístico como testimonio adquiere una nueva semántica en su función de memoria corporal que transmite conocimiento, reconocimiento y dignidad ${ }^{12}$.

\section{Tejiendo esperanzas}

Los tapices, tejidos, textiles, bordados, en cualquiera de sus formas constituye uno de los repertorios más populares y exitosos en los colectivos de mujeres. No es solo un acto simbólico que reafirma la identidad femenina sino que revierte esta misma condición para convertirse en símbolo de poder político. Como en el caso de las famosas arpilleras de Chile, quienes se atrevieron en los momentos de mayor represión del régimen de Pinochet a denunciar los horrores a través de los textiles que representaban los hechos que sucedían en Chile. Del mismo modo, varias asociaciones colombianas expresan el sentir a través de colchas, tejidos, tapices y bordados, donde mezclan sus dolores con la denuncia social y política. Es el caso de las Mujeres Tejedoras de Sueños y Saberes de Paz de Mampuján, en la cosa Atlántica. Esta localidad fue el escenario de una de las masacres efectuadas por parte de Paramilitares, que luego de asesinar impunemente a muchos de los pobladores, ordenaron la retirada de todo el pueblo en marzo del 2000. Tras pasar por numerosos avatares, algunos pobladores regresaron a un lote cerca del pueblo y trataron de rehacer sus vidas en el año 2006. Es en ese escenario, en el que un grupo compuesto por 33 mujeres se reunían para intentar retomar sus vidas. Una predicadora menonita que trabajaba con una ONG les enseñó la técnica del quilt o colchas de retazos. Al principio, las mujeres seguían los patrones tradicionales, pero más adelante descubrieron que en esos retazos de telas podían plasmar los dolores que las atormentan. Fue así como en esos talleres de costura empezaron a aparecer figuras que reflejaban su vida anterior: un vecino, un amigo, un familiar, aquellos que ya no estaban con ellas. En un primer tapiz las mujeres de este colectivo mostraron el día de la salida del pueblo: "se ven figuras de ancianos cargados en hamacas, hombres y mujeres con bultos y niños en brazos. Sujetos uniformados que les apuntan” (Castrillón, 2015). Juana Alicia Ruíz, en una entrevista para la Revista Cromos, declara que la colcha se convirtió "en una catarsis, en una forma de sanar las heridas" (Castrillón, 2015). La experiencia representó una sanación y las conminó a continuar con otros proyectos. Estos tapices empezaron a darse a conocer a través de ayudas financieras que recibieron de la ONU en un recorrido por varias de las localidades que habían experimentado el mismo horror y que se llamó la Ruta por la vida. Recorrieron varios municipios enseñando a las mujeres a sanar sus dolores por

${ }^{12}$ Vea el video sobre el mural en: https://www.youtube.com/watch?v=H1USuh4GKdU 
medio de tapices y de rituales. En cada lugar invitaban a las mujeres a un ritual que consistía en masajes de relajación, almuerzo y sesiones de costura. Cada grupo de mujeres tejían tres tapices: "uno que mostrara su vida antes del conflicto, otro para relatar los hechos violentos, y uno más para visualizar el futuro" (Castrillón, 2015). Actualmente dos de los tapices, Desplazamiento y Masacre hacen parte de la sala Nación y Memoria del Museo Nacional de Bogotá. Estas obras también han recorrido países de Europa y Norteamérica como evidencia del trabajo de sanación de estas mujeres. Al igual que las Arpilleras de Chile, las mujeres de Mampuján han encontrado un cauce a la pérdida y al trauma a través de lo que simboliza el tejido como testimonio: un repertorio simbólico que parte del cuerpo, reconstruyendo la memoria y restableciendo el tejido social.

\section{Magdalenas por el Cauca}

Una de las masacres que ha causado dolor inmenso y repercusiones que aún no terminan fue la de Trujillo, Valle del Cauca, ocurrida durante varios años, desde 1986 hasta 1994 con más de 300 víctimas a manos del narcotráfico, los paramilitares y las fuerzas armadas del estado. En 1995 se funda la Asociación de Familiares de Víctimas de Trujillo- AFAVIT- con el fin de reconstituir los lazos de la comunidad hacia la paz y reparación. Como parte de esa organización surgen también Las Matriarcas de Trujillo, una agrupación de mujeres que lucha por la supervivencia de su comunidad a través de acciones de solidaridad. Es importante anotar que como sucede en gran parte de las masacres de este tipo, la mayoría de los asesinados y desaparecidos eran hombres, por lo que las mujeres como sobrevivientes se convierten en las que cargan con la responsabilidad de reconstituir sus comunidades.

En el caso de Trujillo, los repertorios simbólicos comprenden una variedad de iniciativas que han permitido la supervivencia de los y las sobrevivientes de la región. Entre estas iniciativas se cuenta el Parque Monumento de Trujillo. Este parque se encuentra situado en la colina del pueblo, desde donde se divisa la población y las inmediaciones. Allí se encuentran reunidas varias de las iniciativas: el sendero de la memoria, el osario, la galería y una escuela para niños. Entre los repertorios más significativos que celebran anualmente los pobladores de Trujillo están Las Magdalenas por el Cauca, una peregrinación de balsas de guadua por el río Cauca que portan estandartes con la imagen de las víctimas que fueron asesinadas y desaparecidas en el mismo río durante la época de las masacres. Esta peregrinación tiene su origen en una ancestral tradición de limpiar las aguas y que luego fue adaptada a un ritual religioso católico que resignifica la ceremonia que se efectuaba tradicionalmente el día de las ánimas. Es también, una reelaboración del mito popular de La llorona, la mujer que clama por sus hijos desaparecidos en las 
aguas del río. Es igualmente, una restitución simbólica de la imagen de las víctimas que busca unir los cuerpos desmembrados y desaparecidos y los expone en lienzos gigantes en cada balsa ${ }^{13}$.

Las Magdalenas por el Cauca es una exposición ambulante que se realiza en medio de festejos, música, rezos con la participación de un cortejo compuesto por canoeros, pescadores de las riberas y pobladores que recuerdan a sus muertos. Uno de los íconos más representativos es el del cuerpo decapitado, que recuerda la trágica muerte del párroco Tiberio Fernández, ocurrida en abril de 1990 por intentar defender a la población. Esta imagen se ha convertido en símbolo y se reproduce en cada lugar del pueblo, en las conmemoraciones y en la procesión por el río. Lo más significativo de esta ceremonia es que todo adquiere valor simbólico. Las balsas son estandartes de la memoria, "el río es una metáfora de las lágrimas, del dolor, mientras que el arte sirve como traductor del dolor del alma" (entrevista a Marsella Beltrán, CNRR: 2009).

El Parque monumento reúne una serie de repertorios simbólicos en memoria de las víctimas y de los eventos ocurridos, no solo en Trujillo, sino en el resto del país y en América Latina. El sendero de la memoria construido alrededor del edificio está dedicado a cada una de las masacres ocurridas en Colombia desde 1985. Como una alegoría del Viacrucis de semana santa, cada una de las placas a lo largo del sendero registra una imagen o foto del evento, las fechas de la masacre, los nombres de los culpables con nombres y apellidos, el número aproximado de víctimas y una nota explicativa. El sendero desemboca en el osario, una especie de cementerio sin cuerpos. En cada lápida se representa la figura de la víctima trazada sobre el cemento en alto relieve representando los oficios que desempeñaba en vida y un objeto que lo caracterizaba. Este cementerio ha sido considerado por el padre Javier Giraldo -uno de los acompañantes de las víctimas- como "un sepulcro animado, una cátedra de resistencia, un templo sagrado, una hoguera y un centro de convenciones donde se unen quienes proclaman "nunca más" (CNRR, 2009: 31). ${ }^{14}$ Ludibia Vanegas, una de las matriarcas de Trujillo y Vicepresidenta de Afavit, declaró en una entrevista con las autoras de este ensayo, que ella y sus compañeras han sobrevivido gracias a la labor colectiva de Afavit y de las acciones que desarrollan en el parque monumento. "Afavit nos ha cambiado la vida, ahora podemos hacer nuestro duelo, ahora somos parte de la historia" ${ }^{15}$. Ludibia, como tantas otras mujeres, perdió a sus seres queridos, sus casas y referentes. "Son veintiséis los muertos y desaparecidos de mi familia en las distintas violencias que me ha tocado vivir. Mire, aquí los tengo anotados en esta libretica”, declara Vanegas, al tiempo que asegura

\footnotetext{
13 Esta iniciativa de arte efímero se ha realizado con la dirección de los artistas Gabriel Posada y Yorlady Ruiz. La primera de esas procesiones se realizó en el 2008 y se continúan celebrando cada año en el mes de junio.

${ }^{14}$ Carta del Padre Javier Giraldo citada en Memoria en tiempos de Guerra (CNRR, 2009: 31).

15 Entrevista con Ludibia Vanegas (12 de marzo del 2015 en Trujillo, Colombia).
} 
firmemente, "de aquí no me muevo, así me amenacen y me maten, porque ya no me da miedo, ya no tengo nada que perder" (entrevista, 2015). Como Ludibia, las matriarcas de Trujillo han encontrado el valor y la resiliencia ante el dolor y el sufrimiento, en la fuerza de la colectividad y en los lazos de solidaridad que se tejen en los repertorios simbólicos que restituyen la memoria y el valor simbólico de la vida $^{16}$ Ludibia asegura que el arte y la pintura le ha propiciado un espacio de liberación. Además, los conocimientos adquiridos en los encuentros y talleres le brindan un poder como mujer que ella desconocía. Estos conocimientos se los transmite a su hija y a sus nietos. Su satisfacción se expresa en la certidumbre de que sus hijas no van a pasar por los mismos situaciones que ella experimentó. Ludibia Vanegas se ha convertido en vocera y líder de su comunidad llevando el testimonio de las víctimas de Trujillo a eventos nacionales y sirviendo como enlace con otras organizaciones. Tuvimos la oportunidad de verla en la Cumbre de Arte y Cultura por la Paz en Colombia, hablando ante grandes audiencias con propiedad y determinación, algo que demuestra el poder y agencia adquiridos a través del trabajo colectivo y de los repertorios simbólicos testimoniales.

\section{A manera de conclusión}

Los repertorios analizados en este ensayo demuestran que el testimonio femenino contemporáneo se sitúa en zonas que no ingresan en el orden del discurso. Son experiencias, que como señala Rosana Rodríguez, "tardan en adquirir nominación... que quedan en el reborde de lo enunciado y que no pueden ser plenamente admitidas” (Rodríguez, 2009: 1161). De esta manera, la nueva concepción de repertorios simbólicos testimoniales que proponemos surge de un territorio anterior a la palabra, desde la experiencia corporal. Si tenemos en cuenta que los cuerpos de las mujeres han sido y son territorios de combates, de experiencias hondamente traumáticas difíciles de nombrar, es ahí donde el testimonio encuentra su cauce en los repertorios pre-discursivos, en las prácticas orales, gestuales, culturales y ritualísticas que se elaboran en colectividad. Los repertorios como el teatro, la pintura, el tejido, las balsas ceremoniales por el río Cauca analizadas se constituyen en formas privilegiadas de testimoniar las experiencias traumáticas del conflicto que ha vivido Colombia en expresiones que reafirman una nueva forma de poder y de agencia individual y colectiva.

Colombia hace frente a su historia de dolor a través de diversas formas de expresiones simbólicas. Se trata de un esfuerzo por dignificar a través de repertorios artísticos una cultura viva de resistencia en la

\footnotetext{
16 Trujillo y la zona circundante en el límite del Valle con el Chocó es aún hoy una zona de conflicto donde distintos actores armados se disputan el territorio. En una visita realizada en marzo del 2015 nos sentimos vigiladas por alguna de las fuerzas ocultas que rigen la zona.
} 
construcción de una memoria compartida. Como señala Carlos Satizábal, es un esfuerzo por no repetir los hechos y de promover la dignificación de las víctimas:

[L]a cultura y el arte son valores en sí mismos... Son fines porque ponen en escena deseos, fracturas, rebeldías, transgresiones. Porque producen goce, placer. Goces del corazón, del cuerpo, de la imaginación, del pensamiento; y digo del pensamiento porque el goce estético también es placer de la compresión. (Satizábal, 2014a)

Las mujeres mencionadas en este ensayo reflejan que a través de las rebeldías, transgresiones y resistencias, han logrado transformar su dolor en poder, su cuerpo en locus de resistencia, y sus iniciativas por la memoria y contra la impunidad, las ha convertido en sujetos y agentes de cambio social. 
Elvira Sánchez-Blake y Yenifer Luna. Camino a la paz...

\section{Bibliografía}

AFAVIT (2009). "La memoria: una apuesta por la vida y la dignidad”. Briceño et al. Recordar el conflicto: iniciativas no oficiales de memoria en Colombia. Bogotá, ICTJ: 43- 72.

Beverly, John (1996). “The Real Thing”. The Real Thing: Testimonial Discourse an Latin America. George Gugelberger (ed.). Durham \& London: Duke University Press: 266-287.

Butler, Judith (2001). El grito de Antígona. Trad. Esther Oliver. Barcelona: El Roure.

Castrillón, Gloria. "Las tejedoras de Mampuján: La fuerza femenina del perdón”. Revista Cromos. Bogotá (Lunes, 16/03/2015).

CNRR. Grupo de Memoria Histórica (2009). Memorias en tiempos de guerra: Repertorios de iniciativas. Bogotá: Puntoaparte eds.

Das, Veena (2008). Sujetos del dolor, agentes de dignidad. Francisco Ortega (ed). Bogotá y Medellín: Universidad Javeriana, Instituto Pensar, Universidad Nacional de Colombia y Facultad de Ciencias Humanas-CES.

Jelin, Elizabeth (2002). Los trabajos de la memoria, España: Siglo Veintiuno.

Kaminski, Amy K. Reading the Body Politic: Feminist Criticism and Latin American Women Writers. Minneapolis: University of Minnesota Press.

López Baquero, Constanza (2012). Trauma, memoria y cuerpo: El testimonio femenino en Colombia. Tempe: Asociación Internacional de Literatura y Cultura Femenina Hispánica- AILCFH.

Reátegui Carrillo, Félix (2009). "Las víctimas recuerdan: Notas sobre la práctica social de la memoria". En Briceño et al eds. Recordar el conflicto: iniciativas no oficiales de memoria en Colombia. Bogotá, ICTJ: 17-43.

Rodríguez, Rosana P. "El poder del testimonio: experiencias de mujeres". Revista de Estudios Feministas. 21.3 (2013): 1149-1169.

Satizábal, Carlos (2014 ). “Memoria poética”. Bogotá (manuscrito inédito).

Satizábal, Carlos (2015 ). “Antígonas Tribunal de Mujeres: memoria política y conflicto en Colombia”. Bogotá (manuscrito inédito).

Taylor, Diana (2003). The Archive and the Repertoire: Performing Cultural Memory in the Americas. Durham and London: Duke University Press.

Todorov, T. (2000). Los abusos de la memoria. Trad. Miguel Salazar. Barcelona: Paidos Ibérica. 
Uribe, María Victoria (2009). “Iniciativas no oficiales: un repertorio de memorias vivas”. En Briceño et al, eds. Recordar el conflicto: iniciativas no oficiales de memoria en Colombia. Bogotá, ICTJ: 4372 .

Yúdice, Geroge. “Testimonio y concientización”. Revista de crítica literaria latinoamericana 18.36 (1992): 221-32. 